\title{
El impacto de la jurisprudencia en materia de Derecho Penal Internacional
}

\section{The impact of jurisprudence on international criminal law}

Recibido: 16/07/2021

Aceptado: 16/08/2021

\author{
Norman Reynerio Orellana Pérez \\ Doctorado en Derecho \\ Universidad de San Carlos de Guatemala \\ orellanaprez@gmail.com
}

\section{Referencia del artículo}

Orellana Pérez, N. R. (2021). El impacto de la jurisprudencia en materia de Derecho Penal Internacional. Revista Diversidad Científica, 1(1). 129-140.

DOI: https://doi.org/10.36314/diversidad.v1i1.14

\section{Resumen}

La jurisprudencia de los tribunales penales internacionales ha sido en general, bastante difusa por el hecho de que, hasta el momento de la aparición de la Corte Penal Internacional, cada tribunal internacional se fundamentaba en su propio Estatuto para emitir sus resoluciones. El objetivo de la investigación del presente ensayo es establecer si la jurisprudencia de la Corte Penal Internacional ha sido utilizada por los otros tribunales internacionales y viceversa. La teoría que respalda la presente investigación es la teoría general del Derecho penal internacional en el sentido de determinar si existe un sistema o por lo menos un esbozo del mismo en la jurisprudencia de los tribunales penales internacionales. De las fuentes revisadas puede concluirse que si bien la Corte Penal ha utilizado algunos principios contenidos en resoluciones de tribunales penales internacionales anteriores a su constitución, esta es escaza y que también los otros tribunales penales internacionales vigentes han utilizado escasamente algunas resoluciones de la Corte Penal Internacional, pero ya se esboza un incipiente sistema de jurisprudencia en el ámbito del Derecho penal internacional.

Palabras clave: derecho penal internacional, tribunales penales internacionales, corte penal internacional, estatuto de los tribunales penales internacionales, jurisprudencia en materia de derecho penal internacional 


\begin{abstract}
The jurisprudence of the international criminal courts has been, in general, really fuzzy, because until the time of the appearance of the International Criminal Court, every international court issued their resolutions on their own statute. The purpose of the investigation on this essay is to establish whether the jurisprudence of the International Criminal Court has been used by other international courts and vice versa. The theory that supports this research is the general theory of international criminal law in the sense of determining whether there is a system or, at least, an outline of it in the jurisprudence of international criminal courts. From the sources reviewed, it can be concluded that, although the Criminal Court has used some principles contained in resolutions of the other international criminal courts prior to its constitution, the use has been limited and the other international criminal courts have also barely used some resolutions of the International Criminal Court, but an incipient system of jurisprudence in the field of international criminal law has already been outlined.
\end{abstract}

Keywords: international criminal law, international criminal courts, international criminal court, statute of international criminal tribunals, jurisprudence on international criminal law 


\section{Introducción}

Es un hecho que los tribunales penales internacionales suelen usar los criterios jurisprudenciales de otros tribunales que, aunque pudieran tener una competencia territorial, personal y temporal distinta tienen como función aplicar la responsabilidad penal internacional. Lo interesante de esta práctica es que no hay disposición alguna en los estatutos de estos diversos tribunales que permitan u obliguen al uso de estos criterios; sin embargo, esto no ha sido obstáculo para su empleo cotidiano. Como consecuencia de esta observación deviene necesario buscar patrones y tendencias en este uso de jurisprudencia, dándole continuidad al trabajo relacionado con la comunidad de tribunales.

En el sentido anterior, puede afirmarse que la jurisprudencia es el hilo conductor que le puede dar cohesión al Derecho Penal Internacional, cuando cada tribunal opera con base en su instrumento constitutivo y con base en las reglas ahí previstas.

\section{Contenido}

\section{Utilización del régimen normativo de la Corte Penal Internacional en los fallos de los tribunales penales internacionales 1.1 En el Tribunal Penal Internacional para la Antigua Yugoslavia}

Es interesante observar que, aunque el Tribunal Penal Internacional para la Antigua Yugoslavia precede a la Corte Penal Internacional, el Estatuto de esta última fue citado como referente en las primeras decisiones del tribunal ad hoc. Incluso, se reiteró en diversas ocasiones que se trataba de una colección de normas de derecho consuetudinario internacional, aunque el tratado aún no había entrado en vigor.

La primera expresión de la importancia del Estatuto de la Corte Penal Internacional se puede ver en la resolución de Primera Instancia en el caso Furundzija, que en lo relevante estableció:

Respecto del Estatuto de Roma, éste es un tratado internacional no vinculante aún (puesto que todavía no entra en vigor). Fue adoptado por una abrumadora mayoría de los Estados presentes en la Conferencia Diplomática de Roma y fue apoyado sustancialmente por el Sexto Comité de la Asamblea General el 26 de noviembre de 1998. En muchas áreas, el Estatuto puede ser un reflejo de las posturas legales, es decir, la opinio iuris de una gran cantidad de Estados. A pesar de que el artículo 10 del Estatuto, cuya finalidad es asegurarse de que el derecho existente o en desa- 
rrollo no se vea limitado o perjudicado por las disposiciones del Estatuto, debe tenerse cuidado y utilizar cum grano salis dichas disposiciones para dilucidar derecho consuetudinario internacional. Dependiendo del tema en cuestión, el Estatuto de Roma puede ser usado para reflejar, sugerir o clarificar normas consuetudinarias o cristalizarlas, en tanto crea derecho nuevo en algunas áreas o lo modifica. En todo caso, el Estatuto de Roma en general puede ser tomado como una expresión confiable (authoritative) de las posturas legales de una gran cantidad de Estados (TPIAY, 1998. Párr. 227).

No obstante el palpable escepticismo de esta Sala, en la apelación del caso Tadic se toma una postura distinta, pues se minimizan del carácter crítico del párrafo transcrito enfatizando que muestra características propias de las normas de costumbre internacional al dar por establecida la obligatoriedad jurídica (opinio juris):

"El valor legal que se atribuye actualmente a las disposiciones del Estatuto de Roma ha sido correctamente establecido por la Sala de Juicio II en el caso Furundzija. Allí, la Sala señaló que el Estatuto es aún un tratado internacional no vinculante, ya que no ha entrado en vigor. Sin embargo, ya tiene un valor jurídico importante. El Estatuto fue adoptado por una abrumadora mayoría de los Estados presentes en la Conferencia Diplomática de Roma y fue apoyado sustancialmente por el Sexto Comité de la Asamblea General. Esto demuestra que dicho texto es apoyado por una gran cantidad de Estados y puede ser tomado en cuenta como una expresión de la opinio iuris, tomando en cuenta que la figura de la responsabilidad por coautoría que se discutió está firmemente establecida en el Derecho internacional y difiere de la ayuda y aliento (aidin and abetting) (TPIAY, 1999. Párr. 223).

De forma similar, en el caso Tadic mencionado se citó al Estatuto de la Corte Penal Internacional, en particular el artículo 25 (3) (d) como evidencia de que en el Derecho Internacional hay una norma de costumbre que reconoce la posibilidad de procesar a una persona por participar en un plan común y que dicha forma de imputación es distinta al aiding and abetting.

En el caso Krstic el uso de este instrumento internacional fue reiterado. Se empleó para determinar que el exterminio como crimen de lesa humanidad debe concretarse en la muerte de por lo menos una persona, pero con la intención de buscar la destrucción de parte de la población. De igual manera, se interpretó que "el crimen de lesa humanidad de traslado forzado no se limita al uso de la fuerza física, sino que adopta un significado más amplio" (TPIAY, 2001. Párr. 498). 


\subsection{En el Tribunal Penal Internacional para Ruanda}

Ante el Tribunal Penal Internacional para Ruanda las referencias al derecho penal sustantivo son realmente escasas, aunque se encuentran más menciones al Estatuto de la Corte Penal Internacional y la jurisprudencia de la Corte Penal Internacional con relación a cuestiones procesales.

Una de las menciones al Derecho penal sustantivo se encuentra en el caso Baglishema en el que se tuvo que determinar si los crímenes de lesa humanidad debían cometerse con un elemento de discriminación constitutivo del elemento subjetivo (mens rea) de la conducta o la descripción del ataque como elemento contextual de este crimen. La Sala de Primera Instancia hizo notar que "sólo el Estatuto del Tribunal Penal Internacional para Ruanda contiene dicha descripción del ataque, no está previsto este elemento discriminatorio en el Estatuto de la Corte Penal Internacional o en otro instrumento de Derecho Penal Internacional" (TPIR, 2001, párr. 81).

Una nota interesante es lo que se presentó en el caso Karemera et al en el que uno de los acusados (Joseph Nzirorera) impugnó la práctica de la Fiscalía de preparar testigos, casi exclusivamente con base en una determinación de la Sala de Cuestiones Preliminares y de la Corte Penal Internacional en la que no se había encontrado que dicha práctica tuviera un sustento en el Derecho Internacional. La Sala de Apelaciones se negó a seguir el criterio de la Corte Penal Internacional y permitió que la Fiscalía del Tribunal Penal Internacional para Ruanda preparara con bastante libertad la declaración de los testigos, señalando que en el Derecho Penal Internacional no hay un sistema de precedentes. Argumentaron que, "si dentro del mismo sistema del Tribunal Penal Internacional para Ruanda no existe un carácter vinculante entre resoluciones de primera instancia, con mayor razón no son obligatorios los criterios de otros tribunales" (TPIR, 2007, párr. 7).

\subsection{En la Corte Especial para Sierra Leona}

En la Corte Especial para Sierra Leona (CESL) también se encuentran diversas referencias al Estatuto de la Corte Penal Internacional; así como diversos instrumentos internacionales aplicables ante la Corte Penal Internacional. Hay una notable diferencia con los tribunales ad hoc, ya que la Regla 72 bis de las Reglas de Procedimiento y Prueba de la CESL establece el derecho aplicable, de forma similar al artículo 21 del Estatuto de la Corte Penal Internacional. En un segundo inciso se precisa que se podrán aplicar de forma supletoria principios y reglas de derecho consuetudinario internacional. 
En la argumentación inicial no se menciona el papel que juegan los Elementos de los Crímenes. Esto se resolvió hasta la apelación, donde se aclaró que "se trata de un documento que tiene como finalidad ayudar a interpretar a la Corte Penal Internacional el alcance de los elementos típicos de los crímenes de su competencia" (TESL, 2009, párr. 578). Así, la propia Corte Especial para Sierra Leona puede auxiliarse de este documento, pero no porque sea el reflejo de la costumbre internacional.

En el caso particular, la Sala de Apelaciones consideró que las disposiciones de los Elementos de los Crímenes eran el reflejo de costumbre internacional de la toma de rehenes como crimen de guerra, dado que se había retomado la Convención Internacional sobre la Toma de Rehenes lo cual le daba un sustento adicional.

Al aplicar los principios antes expresados la Sala de Primera Instancia usa indistintamente el Estatuto de la Corte Penal Internacional, los Elementos de los Crímenes y la jurisprudencia de los tribunales ad hoc, ya sea para identificar una norma de costumbre internacional o para precisar los elementos típicos y su interpretación. Esto ocurrió con respecto a los crímenes de violación (como crimen de guerra y como crimen de lesa humanidad), esclavitud sexual, ultrajes a la dignidad humana, mutilaciones como crimen de guerra, pillaje, ataque contra personal de misiones de paz y toma de rehenes como crimen de guerra.

De esta sentencia hay dos cosas que se deben destacar. Por un lado, se cita la resolución de confirmación de cargos en el caso Lubanga para definir el crimen de alistamiento de menores de 15 años de edad. De igual forma para establecer una diferencia entre utilizar, alistar y reclutar a menores de 15 años en las hostilidades, se fundamenta en los trabajos de las Comisiones Preparatorias de la Corte Penal Internacional.

\section{Régimen normativo de los tribunales penales internacionales en la Corte Penal Internacional \\ 2.1 Regla para la aplicación de la jurisprudencia de los tribunales ad hoc}

A diferencia de los tribunales ad hoc, la Corte Penal Internacional ha establecido una regla clara para la aplicación de la jurisprudencia de los tribunales que le precedieron. En esencia esta regla señala que la jurisprudencia de otros tribunales penales internacionales puede emplearse siempre y cuando sea compatible con el derecho aplicable según el Estatuto de la Corte Penal Internacional. Se ha reite- 
rado que la aplicación de estos criterios no es automática, dado que las normas que le dieron origen o que interpretan pueden ser diferentes a las que se encuentran en el marco jurídico de la Corte Penal Internacional.

En concreto, la Corte Penal Internacional ha establecido siguiendo el texto del artículo 21 del Estatuto Corte Penal Internacional que "en primer lugar aplicará el propio Estatuto, las Reglas de Procedimiento y Prueba y los Elementos de los Crímenes. En segundo lugar, cuando proceda, los principios y normas de Derecho internacional" (CIJ, 2007, párr. 44).

Estos principios y normas se pueden desprender de la jurisprudencia de los tribunales ad hoc; siempre y cuando sean compatibles con el marco normativo primario de la Corte Penal Internacional. En otras palabras, que no contravenga el Estatuto de la Corte Penal Internacional, las Reglas de Procedimiento y Prueba y los Elementos de los Crímenes y, preferentemente, que se parta del mismo esquema normativo o de la misma norma jurídica, de tal forma que la interpretación sea compatible.

En temas sustantivos es emblemático el caso del genocidio. La definición de este crimen internacional es idéntica en la Convención para Prevenir y Sancionar el Crimen de Genocidio, el Estatuto del Tribunal Penal Internacional para la Antigua Yugoslavia, el Estatuto del Tribunal Penal Internacional para Ruanda y en el Estatuto de la Corte Penal Internacional. Sin embargo, la Sala de Cuestiones Preliminares I consideró que:

(...) debería adoptarse adicionalmente el elemento contextual previsto en los Elementos de los Crímenes para excluir actos aislados. Esta es la primera vez en más de 60 años en que se cambia la definición típica del genocidio y se realiza con base en un documento interpretativo como los Elementos de los Crímenes (ClJ, 2009, párr. 118).

No obstante, ilustra cómo la Corte Penal Internacional no sólo da prioridad al Estatuto de la Corte Penal Internacional sino a todo el marco normativo primario. Esta regla tiene dos consecuencias. En primer lugar, se formula claramente el método para emplear la jurisprudencia de los tribunales ad hoc, confirmando que se le da prioridad al marco jurídico del órgano judicial en cuestión y, en particular, al estatuto de creación. En segundo lugar, esta regla permite hacer un análisis cualitativo de la interpretación o norma jurídica que implique determinar si efectivamente se acata. 


\subsection{La teoría del reciclaje}

Existe un fenómeno que se ha dado en algunos casos concretos en los que el Estatuto de la Corte Penal Internacional establece una regla de derecho, que puede o no, ser parte de la costumbre internacional, que es retomada por la jurisprudencia de los tribunales ad hoc. Posteriormente, este criterio expresado por los tribunales ad hoc es retomado por la Corte Penal Internacional.

De esta forma, la regla de derecho tiene una utilización cíclica que empieza en la Corte Penal Internacional y termina en la propia Corte Penal Internacional. Lo interesante de este fenómeno es que la Corte Penal Internacional puede hacer una mención o interpretación directa del Estatuto de la Corte Penal Internacional, pero recurre a los tribunales ad hoc.

\subsubsection{Elementos contextuales de los crímenes de lesa humanidad}

Este caso quizá sea de los más evidentes pues a diferencia de los Estatutos del Tribunal Penal Internacional para Ruanda y el Estatuto de la Corte Penal Internacional en el ámbito del Tribunal Penal Internacional para la antigua Yugoslavia no se prevén como elementos contextuales el ataque generalizado o sistemático contra la población civil. Sin embargo, este tribunal ha hecho referencia al Estatuto de la Corte Penal Internacional, entre otros documentos, para justificar su utilización.

En la sentencia de primera instancia en el caso Tadic se señala que el ataque puede ser generalizado o sistemático, es decir que no es necesario que se actualicen ambas características. Entre las fuentes que utiliza para justificar esta interpretación se encuentran los trabajos preparatorios del Estatuto de la Corte Penal Internacional, donde si bien no se cita directamente el Estatuto de la Corte Penal Internacional, en el texto final se refleja esta manera de entender los elementos contextuales.

Derivado de lo anterior, la Sala de Apelaciones del Tribunal Penal Internacional para la Antigua Yugoslavia ha desarrollado los contenidos de los términos generalizado y sistemático. Así, se ha señalado que "por generalizado se entiende un ataque que se realiza a gran escala, con un número importante de víctimas" (TPIAY, 1997, párr. 647). 


\subsubsection{Exclusión del elemento discriminatorio en los crímenes de lesa humanidad}

Durante mucho tiempo se pensó que los crímenes de lesa humanidad se deben cometer con un objetivo discriminatorio en contra de un grupo en particular. Este elemento discriminatorio se vio reflejado en algunas tipificaciones como la prevista en el Estatuto del Tribunal Penal Internacional para Ruanda, cuyo artículo 3 señala:

El Tribunal Internacional para Ruanda está habilitado para juzgar a los presuntos responsables de los siguientes crímenes (de lesa humanidad) cuando éstos han sido cometidos en el curso de un ataque generalizado y sistemático, y dirigidos contra cualquier población civil en razón de su nacionalidad o pertenencia a un grupo político, étnico, racial o religioso...

En el caso Tadic se tuvo que resolver si dicho elemento discriminatorio era aplicable al propio tribunal. Así, apoyándose en los trabajos preparatorios del Estatuto de la Corte Penal Internacional y en el artículo 7 del propio Estatuto, llegó a la conclusión de que había desaparecido este elemento característico del ataque durante el gradual desarrollo en la costumbre internacional.

\subsubsection{Reclutamiento, alistamiento y utilización de menores de quin- ce años en un conflicto armado}

El tema en esta discusión jurisprudencial se centra en determinar el alcance de las tres conductas que constituyen crímenes de guerra en contra de menores de 15 años en los conflictos armados. A diferencia de los casos anteriores, esta forma de reciclaje se da con la Corte Especial para Sierra Leona y no con los tribunales ad hoc.

En el caso AFRC la Sala de Primera Instancia II hace una distinción entre la conscripción de niños soldados, la cual considera que no se limita a incorporación a las fuerzas armadas gubernamentales, sino que puede ser a cualquier grupo armado organizado; pero en todo caso es por la fuerza. 


\section{Conclusión}

Desde la perspectiva de la Corte Especial para Sierra Leona resulta relevante que se cite al Estatuto de la Corte Penal Internacional como un ejemplo de codificación de la costumbre internacional. Asimismo, aunque no se menciona directamente al Estatuto de la Corte Penal Internacional, si se mencionan los antecedentes del mismo. Estos puntos comprueban la teoría del reciclaje en este tema. Se parte del carácter consuetudinario del Estatuto de la Corte Penal Internacional y de sus antecedentes para precisar el alcance de la utilización de menores en las hostilidades. Luego estas interpretaciones son retomadas por la Corte Penal Internacional para interpretar este crimen de guerra. Sólo se puede agregar que no se aportó nada nuevo por la Corte Especial para Sierra Leona como en los ejemplos anteriores, pero si se cumple con el ciclo.

\section{Declaración}

El estudio se realizó de acuerdo al Código de Ética y Buenas Prácticas COPE.

\section{Conflicto de intereses}

El autor declara no tener ningún conflicto de intereses.

\section{Referencias}

Corte Internacional de Justicia. Demandante vs. Al Bashir. Decisión sobre la aplicación del demandante para una orden de detención contra Omar Hassan Ahmad Al Bashir. Cámara de Ante-Juicio I. Caso No. ICC-02/05-01/09-3. 4 de marzo de 2009.

Corte Internacional de Justicia. Demandante vs. Lubanga. Decisión sobre las prácticas utilizadas para preparar y familiarizar a los testigos para dar testimonios en juicios. Cámara de Prueba I. Caso No. ICC-01/04-01/06-1049. 30 de noviembre de 2007. 
Tribunal Especial para Sierra Leona. Demandante vs. Issa assan Sesay, Morris Kallon y Augustine Gbao. Juicio de apelación. Cámara de Apelaciones. Caso No. SCSL-04-15-T. 26 de octubre de 2009.

Tribunal Penal Internacional para la Antigua Yugoslavia. Demandante vs. Furundzija. Juicio. Cámara de Prueba. Caso No. IT-95-17/1-T. 10 de diciembre de 1998.

Tribunal Penal Internacional para la Antigua Yugoslavia. Demandante vs. Krstic. Juicio. Cámara de Pruebas II. Caso No. IT-98-33-T. 2 de agosto de 2001.

Tribunal Penal Internacional para la Antigua Yugoslavia. Demandante vs. Tadic. Juicio. Cámara de Apelaciones. Caso no. IT-94-1-A. 15 de Julio de 1999.

Tribunal Penal Internacional para la antigua Yugoslavia. Demandante vs. Tradic. Juicio de prueba. Cámara de Prueba. Caso No. IT-94-1-T. 7 mayo de 1997.

Tribunal Penal Internacional para Ruanda. Demandante vs. Édouard Karemara, Mathieu Ngirumpatse, Joseph Nzirorera. Decisión sobre la apelación interlocutoria sobre la prueba de testigos. Cámara de Apelaciones. Cano No. ICTR-98-44-T. 11 de mayo de 2007.

\section{Sobre el autor \\ Norman Reynerio Orellana Pérez}

Licenciado en Ciencias Jurídicas y Sociales, Abogado y Notario, Maestría en Derecho Penal, Maestría en Derecho Civil y Procesal Civil, Maestría en Derecho Constitucional, Postgrado en Administración Pública, Maestría en Administración Pública (Distinción Magna Cum Laude), Doctorado en Derecho. Publicación de ensayo "Evolución del Derecho Penal después de los atentados de las Torres Gemelas, La evolución del Derecho Penal del Enemigo", publicación de Monografía "El Derecho Penal Internacional como Sistema Jurídico-Penal”. 


\section{Copyright (c) Norman Reynerio Orellana Pérez}

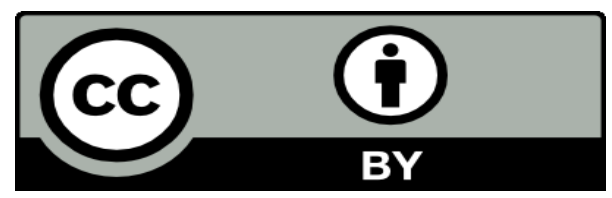

Este texto está protegido por una licencia CreativeCommons 4.0.

Usted es libre para compartir, copiar y redistribuir el material en cualquier medio o formato y adaptar el documento, remezclar, transformar y crear a partir del material para cualquier propósito, incluso comercialmente, siempre que cumpla la condición de atribución: usted debe reconocer el crédito de una obra de manera adecuada, proporcionar un enlace a la licencia, e indicar si se han realizado cambios. Puede hacerlo en cualquier forma razonable, pero no de forma tal que sugiera que tiene el apoyo del licenciante o lo recibe por el uso que hace. 